\title{
Manejo do solo e adubação nitrogenada na supressão de plantas daninhas na cultura do feijão de inverno e irrigado ${ }^{1}$
}

\author{
Soil management and nitrogen fertilization on weed suppression on winter irrigated \\ common bean
}

\author{
Marion Martins Vincensi ${ }^{2}$, Érica de Oliveira Araújo ${ }^{3 *}$, Hamilton Kikuti ${ }^{4}$ e Marcos Antonio Camacho ${ }^{5}$
}

\begin{abstract}
Resumo - Objetivou-se avaliar diferentes plantas de coberturas do solo e a adubação nitrogenada na supressão de plantas daninhas na cultura do feijão de inverno e irrigado. O delineamento experimental utilizado foi o de blocos casualizados em esquema de parcelas subdivididas, constituído por quatro blocos e quatro repetições. Nas parcelas foram utilizados manejos de cobertura de solo (milheto, crotalaria juncea, sem cobertura e vegetação espontânea). Nas subparcelas utilizou-se a presença e ausência de nitrogênio em cobertura no feijoeiro aos 20 DAE. Foram avaliadas as massas verdes e secas das plantas de coberturas antes da incorporação no solo. Após 35 dias da emergência do feijoeiro avaliou-se a massa seca, o número de espécie, número total de plantas daninhas por $\mathrm{m}^{2}$ e a porcentagem de incidência de plantas daninhas (observações visuais). Com base nos resultados o manejo do solo com crotalária conferiu maior supressão às plantas daninhas, devido à quantidade de massa no solo. A adubação nitrogenada em cobertura na cultura do feijão influenciou significativamente a produção de massa seca pelas plantas daninhas. A liberação acelerada do nitrogênio pela crotalária favorece a ocorrência e o estabelecimento de algumas espécies de plantas daninhas, conferindo alta competitividade por parte da planta daninha, e conseqüentemente favorecendo a produção de massa seca.
\end{abstract}

Palavras-chave - Phaseolus vulgaris L. Nitrogênio. Manejo cultural de plantas daninhas.

\begin{abstract}
The objective of this work was to evaluate the different roof plants and soil nitrogen fertilization in weed suppression on winter irrigated common bean. The experimental scheme used was randomized blocks in subdivided parcels, consisting on four blocks and four replications Soil management coverage was used within the plots (millet, crotalaria juncea, without coverage and spontaneous vegetation).Subplots used the presence and absence of nitrogen, on coverage, at 20 DAE .Dry and wet weight of the plants were evaluated before incorporation into the soil. After 35 days of the emergence of the bean plant, were assessed the dry mass, the number of species, the number of total weeds per $\mathrm{m}^{2}$ and the percentage of weed incidence (visual observations). The results have shown that the soil with crotalaria gave greater suppression on weeds, due to the amount of mass in the soil. The fertilization in coverage influenced significantly the production of dry mass of weeds. The accelerated release of nitrogen by crotalaria favors the occurrence and establishment of some species of weeds, giving high competitiveness on the part of the weed and consequently favoring dry mass production.
\end{abstract}

Key words - Phaseolus vulgaris L. Nitrogen. Weed cultural management.

\footnotetext{
* Autor para correspondência

${ }^{1}$ Recebido para publicação em 03/09/2010; aprovado em 20/04/2011

Parte da Dissertação de Mestrado do primeiro autor apresentada ao Programa de Pós-Graduação em Agronomia-Produção Vegetal, UEMS

${ }^{2}$ Universidade Estadual de Mato Grosso do Sul-UEMS, Unidade Universitária de Aquidauana, Rod. Aquidauana/Piraputanga km 12, Aquidauana-

MS, Brasil, 79.200-000, marionvincensi@hotmail.com

${ }^{3}$ Doutoranda do Programa de Pós-Graduação em Agronomia-Produção Vegetal, Universidade Federal da Grande Dourados-UFGD, Rod. Dourados/ Itahum, km 12, Cidade Universitária, Dourados-MS, Brasil, 79.804-970, (67) 3910.2756, ericabb25@hotmail.com

${ }^{4}$ Departamento de Agronomia da Universidade Estadual de Mato Grosso do Sul,UEMS, Unidade Universitária de Casssilândia, Rod. MS 306, Km 06, Cassilândia-MS, Brasil, 79.540-000, hkikuti@hotmail.com

${ }_{5}^{5}$ Departamento de Agronomia da Universidade Estadual de Mato Grosso do Sul, Rod. Aquidauna/Piraputanga, km 12, Aquidauana-MS, Brasil,

79.200-000, camacho@uems.br
} 


\section{Introdução}

As plantas de cobertura utilizadas no manejo de solo melhoram as condições para cultivo devido a melhor aeração proporcionada e da diminuição da temperatura do solo e da evapotranspiração durante o ciclo de cultivo do feijoeiro (STONE; MOREIRA, 2000). Além destas vantagens são capazes de suprimir a infestação das plantas daninhas.

A composição de uma população de plantas daninhas pode ser modificada por plantas de cobertura cultivadas como manejo do solo, reduzindo significativamente a sua emergência e desenvolvimento. Quando não manejadas de modo adequado, essas plantas podem causar redução na produtividade, e algumas delas podem prejudicar a qualidade do produto colhido, aumentando custos e reduzindo a produção. Fávero et al. (2001) avaliando as modificações na população de plantas daninhas na presença de adubos verdes observaram que o uso das leguminosas promoveu modificações na dinâmica de sucessão das espécies daninhas.

Conforme Theisen et al. (2000) e Fávero et al. (2001) dois fatores principais contribuem para a supressão das plantas daninhas: a barreira física imposta pela quantidade das plantas de cobertura depositadas sobre o solo, disponibilizando menor incidência de luz para as sementes, provocando um desenvolvimento insatisfatório das plantas daninhas e a barreira biológica, onde um grupo de substâncias é secretado pelas raízes ou pela decomposição do material vegetal (palha) suprimindo as plantas daninhas. Este grupo de substâncias, denominado de aleloquímicos, são liberados no ambiente desenvolvendo uma importante função ecológica.

A cultura do feijão é exigente em nutrientes, principalmente o nitrogênio, que tem contribuído com altas produtividades. De acordo com Rosolem (1987), o melhor aproveitamento desse nutriente se dá quando aplicado no máximo até 36 dias após a emergência do feijoeiro. Nesse período pode haver ocorrência de plantas daninhas na cultura e há uma competição por $\mathrm{N}$ entre plantas daninhas e o feijoeiro. Lindquist et al. (2010) para a cultura do milho consideraram que na competição com plantas daninhas, o nitrogênio foi o fator mais importante para reduções de produtividade. Procópio et. al (2004) analisando a absorção e utilização de nitrogênio nas culturas da soja, feijão e plantas daninhas, verificaram que o fornecimento de $\mathrm{N}$ favoreceu mais as espécies de plantas daninhas não pertencentes à leguminosas do que as culturas da soja e do feijão. Por outro lado, de acordo com Shafiq et al. (1994), aplicações de $\mathrm{N}$ podem reduzir a pressão de competição das plantas daninhas com determinadas culturas, por incrementar o crescimento e a habilidade competitiva das plantas cultivadas.
A adoção de um sistema que possibilite melhorar as condições do solo, associado ao fornecimento de nitrogênio e controle das plantas daninhas, além de aumentar a eficiência da planta na utilização dos recursos disponíveis, possibilita aumento de produtividade da cultura. O objetivo do presente trabalho foi avaliar diferentes plantas de cobertura do solo e a adubação nitrogenada na supressão de plantas daninhas na cultura do feijão de inverno e irrigado.

\section{Material e métodos}

O experimento foi conduzido no Setor de Produção Vegetal da Universidade Estadual de Mato Grosso do Sul, UEMS, Aquidauana-MS, cujas coordenadas geográficas são: $20^{\circ} 28^{\prime} \mathrm{S}$ e $55^{\circ} 48^{\prime} \mathrm{W}$, e altitude de 207 metros, no ano agrícola de 2009 . O solo foi classificado segundo o Sistema Brasileiro de Classificação de Solos (EMBRAPA, 2006), como ArgissoloVermelho-Amarelo distrófico, textura média/argilosa, cujos resultados de análise química e granulométrica, da camada de $0-20 \mathrm{~cm}$ de profundidade, apresentaram: $\mathrm{pH}\left(\mathrm{CaCl}_{2}\right) 5,1 ; \mathrm{P}: 68,8 \mathrm{mg} \mathrm{dm}^{-3} ; 1,5 \%$ de M.O; K: 0,52 $\mathrm{cmol}_{\mathrm{c}} \mathrm{dm}^{-3}$; Ca: 3,5 $\mathrm{cmol}_{\mathrm{c}} \mathrm{dm}^{-3}$; $\mathrm{Mg} 1,2$ $\mathrm{cmol}_{\mathrm{c}} \mathrm{dm}^{-3} ; \mathrm{Al}: 0,2 \mathrm{cmol}_{\mathrm{c}} \mathrm{dm}^{-3} ; \mathrm{H}+\mathrm{Al}: 4,1 \mathrm{cmol}_{\mathrm{c}} \mathrm{dm}^{-3} ; \mathrm{S}$ : $5,22 \mathrm{cmol}_{c} \mathrm{dm}^{-3} \mathrm{e} \mathrm{T}: 9,32 \mathrm{cmol}_{\mathrm{c}} \mathrm{dm}^{-3}$. O clima da região é do tipo $\mathrm{AW}$, tropical-quente sub-úmido (com estação chuvosa no verão e seca no inverno), segundo a classificação de Koppen (VIANELLO; ALVES, 1991). Na Figura 1 encontram-se a distribuição da precipitação e temperatura média mensal durante a condução do experimento.

O delineamento experimental utilizado foi em blocos casualizados em esquema de parcelas

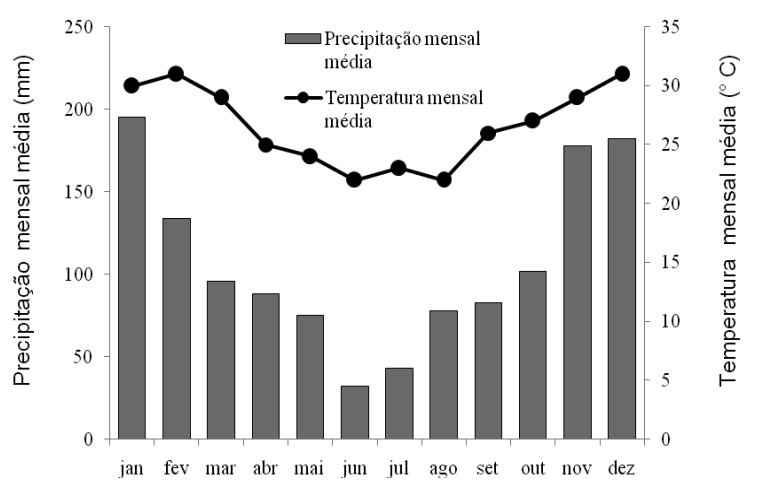

Fonte: INME

Figura 1 - Precipitação $(\mathrm{mm})$ e temperatura $\left({ }^{\circ} \mathrm{C}\right)$ médias mensais para o ano de 2009 
subdivididas, constituído por quatro blocos e quatro repetições. Nas parcelas foram utilizados os manejos de cobertura de solo (milheto, crotalária júncea, sem cobertura e vegetação espontânea). Nas subparcelas utilizou-se a presença ou ausência de nitrogênio em cobertura no feijoeiro aos 20 DAE. O nitrogênio utilizado foi na forma de uréia $(45 \%$ de N) aplicando $90 \mathrm{~kg} \mathrm{ha}^{-1}$ de $\mathrm{N}$ em filete contínuo lateralmente à fileira de plantas.

Para implantar os diferentes manejos do solo antecedentes ao cultivo do feijoeiro, foram dimensionadas dezesseis parcelas de 4 × 35 metros, totalizando uma área experimental de 0,22 ha. Em dois tratamentos foram semeadas as culturas do milheto e crotalária na quantidade de 15 e $35 \mathrm{~kg}$ de sementes por hectare, respectivamente. Outro manejo de solo conduzido foi o de coberturas espontâneas onde a área permaneceu com as coberturas vegetais oriundas do banco de sementes do solo. O último tratamento de manejo de solo instalado foi a testemunha, onde as parcelas permaneceram sem plantas de cobertura até a semeadura do feijoeiro.

Noventa dias após os manejos, foi realizada a incorporação das plantas de cobertura, utilizando uma grade do tipo niveladora para implantação posterior da cultura de feijão. A semeadura foi realizada no dia 01/06/2009 utilizando a cv. pérola, na safra de inverno. A semeadora foi regulada para distribuir 18 sementes de feijão por metro de sulco à profundidade de $4 \mathrm{~cm}$, com espaçamento de $0,45 \mathrm{~m}$ entre fileiras de plantas, e estande final de 15 plantas por metro de sulco nas parcelas. A adubação de semeadura constou da aplicação, em todos os tratamentos de $380 \mathrm{~kg} \mathrm{ha}^{-1}$ da formula NP-K 04-20-20 a uma profundidade de $10 \mathrm{~cm}$. O sistema de irrigação utilizado foi o de aspersão convencional. O aspersor utilizado foi o da marca Agropolo ${ }^{\circledR}$, com pressão de serviço de 30 m.c.a. de vazão de $2,87 \mathrm{~m}^{3} \mathrm{~h}^{-1}$, instalados a $1,0 \mathrm{~m}$ do solo e espaçados a $12 \mathrm{~m}$ entre si. A área foi irrigada através da sobreposição dos jatos de água aplicada pelos aspersores. O regime hídrico total (irrigação + chuva) durante a condução do experimento foi de $402 \mathrm{~mm}$.

Foram determinadas a massa verde e seca das plantas de coberturas antes da incorporação no solo, amostrando uma área útil de $0,5 \mathrm{~m}^{2}$ por parcela. Após 35 dias da emergência do feijoeiro avaliou-se a massa seca, o número de espécies, o número total de plantas daninhas por $\mathrm{m}$ e a porcentagem de incidência de plantas daninhas (observações visuais). Os dados foram submetidos à análise de variância pelo teste $\mathrm{F}$ a 5\% de significância. As análises foram realizadas com o auxílio computacional do programa de análise estatística Statistical Analysis System (SAS).

\section{Resultados e discussão}

A partir da análise de variância, foi verificado efeito significativo do manejo do solo, ao nível de significância de 5\%, para as variáveis massa verde, massa seca das plantas de cobertura, massa seca de plantas daninha (MSPD), número de espécies (NE), número total de plantas daninhas (NT) e porcentagem de incidência (PI), enquanto que, a adubação nitrogenada influenciou apenas na massa seca de plantas daninhas (MSPD) (TAB. 1 e 2). Com relação à interação $\mathrm{M}$ x N, não foi encontrada resposta significativa para nenhuma das variáveis estudadas, conforme mostrado na Tabela 1 e 2 .

Na Tabela 3 são apresentados os valores médios de massa verde e massa seca das plantas de cobertura.

Observou-se que o manejo do solo com crotalária proporcionou produção de massa verde e seca superior e diferiu estatisticamente dos demais tratamentos. Essa produção de massa seca superior da crotalária proporcionou supressão às plantas daninhas (TAB.3), devido à quantidade de massa no solo. Monquero et al. (2009) constatou que o efeito significativo da Crotalária juncea na germinação de plantas daninhas, é devido a influência física da palhada dessa espécie. Segundo Calegari (1998), a crotalária leva vantagens em relação a outras culturas porque exige pouco nutriente do solo e possui rápido desenvolvimento. Conforme Meschede et al. (2007) é importante que as espécies de plantas daninhas sejam manejadas utilizando coberturas vegetais que promovam boa cobertura e maior acúmulo de massa seca, visando possibilitar menor emergência de espécies daninhas durante o ciclo das culturas.

O manejo do solo com coberturas espontâneas apresentou menor massa seca de cobertura quando comparado à crotalária e ao milheto (TAB. 3). Resultados semelhantes foram obtidos por Meschede et al. (2007) quando avaliaram a massa seca das diferentes plantas de cobertura, no Cerrado.

A massa seca das plantas daninhas foi influenciada pelos manejos de solo SC e EI, que proporcionaram maiores valores quando comparadas as médias pelo teste de Tukey a $5 \%$ de significância (TAB. 4). A superfície do solo descoberta, além de receber maior quantidade de luz, também tem maior alternância de temperaturas, o que pode estimular a germinação de grande número de espécies. Vidal e Trezzi (2004) observaram reduções de $41 \%$ de infestação e de $74 \%$ de massa seca total de plantas daninhas comparando as áreas cobertas com culturas à testemunha descoberta. Contudo, a rápida acumulação de massa seca de uma planta resulta em aumento na demanda e, conseqüentemente, na absorção de 
Tabela 1 - Resumo da análise de variância para massa verde e massa seca das plantas de cobertura obtidas antes da semeadura do feijoeiro comum

\begin{tabular}{|c|c|c|c|}
\hline \multirow{2}{*}{ Causa da variação } & \multirow{2}{*}{ GL } & \multicolumn{2}{|c|}{--------------Quadrado Médio----------------- } \\
\hline & & Massa verde & Massa seca \\
\hline Bloco & 3 & $71,417^{*}$ & $38097,1^{*}$ \\
\hline Manejo (M) & 3 & $754,503 *$ & $118891365,4^{*}$ \\
\hline Nitrogênio (N) & 1 & $72,3^{\mathrm{NS}}$ & $32,3^{\mathrm{NS}}$ \\
\hline $\mathrm{M} \times \mathrm{N}$ & 3 & $7836,3^{\mathrm{NS}}$ & $4836,3^{\mathrm{NS}}$ \\
\hline Erro & 27 & 29,819 & 3831,1 \\
\hline CV (\%) & & 29,44 & 1,08 \\
\hline
\end{tabular}

*Significativo a $5 \%$ de significância ${ }^{\mathrm{NS}}$ não significativo

Tabela 2 - Resumo da análise de variância para número de espécies (NE), número total de plantas daninhas (NT) e porcentagem de incidência (PI) em função dos diferentes manejos de solo e adubação nitrogenada

\begin{tabular}{cccccc}
\hline \multirow{2}{*}{ Causa da variação } & GL & \multicolumn{4}{c}{ Quadrado Médio } \\
\cline { 3 - 6 } & & MSPD & NE & NT & PI \\
\hline Bloco & 3 & $71,417^{*}$ & $2,781^{*}$ & $28,375^{*}$ & $202,750^{*}$ \\
Manejo (M) & 3 & $754,503^{*}$ & $26,864^{*}$ & $830,375^{*}$ & $3823,666^{*}$ \\
Nitrogênio (N) & 1 & $72,3^{*}$ & $5,281^{\mathrm{NS}}$ & $72,000^{\mathrm{NS}}$ & $364,500^{\mathrm{NS}}$ \\
A x B & 3 & $1,69^{\mathrm{NS}}$ & $0,28^{\mathrm{NS}}$ & $3,16^{\mathrm{NS}}$ & $3,18^{\mathrm{NS}}$ \\
Erro & 27 & 29,819 & 0,718 & 21,604 & 78,375 \\
\hline CV (\%) & & 29,44 & 18,20 & 19,11 & 18,98 \\
\hline
\end{tabular}

*Significativo a 5\% de significância Ns não significativo

Tabela 3 - Médias de massa seca e massa verde das plantas de cobertura obtidas antes da semeadura do feijoeiro comum

\begin{tabular}{ccc}
\hline \multirow{2}{*}{ Manejo do solo } & Massa verde & Massa seca \\
\cline { 2 - 3 } & $\mathrm{t} \mathrm{ha}^{-1}$ & $\mathrm{~kg} \mathrm{ha}^{-1}$ \\
\hline SC & 0,0 & 0,0 \\
EI & $9,80 \mathrm{~b}$ & $3060,0 \mathrm{c}$ \\
MI & $10,20 \mathrm{~b}$ & $6253,0 \mathrm{~b}$ \\
CI & $20,60 \mathrm{a}$ & $7848,0 \mathrm{a}$ \\
\hline
\end{tabular}

SC: Sem cobertura; EI: Espontâneas incorporadas; MI: Milheto incorporado e CI: Crotalária incorporada; *Significativo a 5\% de significância Ns não significativo

nutrientes pelas raízes. A produção elevada de massa seca por plantas daninhas as tornam mais competitivas em relação a uma cultura.

O maior número de espécies de plantas daninhas emergidas foi observado no tratamento sem plantas de cobertura não diferindo estatisticamente do manejo com plantas espontâneas (TAB. 4). Provavelmente a ausência de cobertura vegetal no tratamento SC pouco limitou a emergência das plantas daninhas. Do mesmo modo a baixa quantidade de cobertura do solo no manejo EI (massa seca de $3.060 \mathrm{~kg} \mathrm{ha}^{-1}$ ), proporcionou uma menor supressão das plantas daninhas quando comparado com CI e MI. Meschede et al. (2007) observaram que a baixa quantidade de massa seca produzida pelas culturas do 
milho e mamona para cobertura de solo, proporcionaram maior emersão das plantas daninhas, quando comparadas com as culturas da crotalaria, do milheto e sorgo.

Notou-se que o tratamento SC proporcionou uma maior emergência total das infestantes e maiores porcentagens de presença de planta daninha, tendo diferido estatisticamente dos demais tratamentos (TAB. 4). Isto ocorreu devido à falta de barreiras físico/biológica proporcionada pelo material vegetal no solo.

Houve diferença significativa da aplicação do nitrogênio em cobertura no feijão para a massa seca das plantas daninhas aos 35 DAE do feijoeiro (TAB. 4). O número de espécies, número total de plantas daninhas e porcentagem de incidência foram superiores quando comparados ao manejo do solo sem aplicação da adubação nitrogenada, mas estatisticamente não diferiram entre si (TAB. 4). Blackshaw et al. (2003) observaram que as massas secas da parte aérea e das raízes de 23 espécies de plantas daninhas apresentaram aumento com a adição de $\mathrm{N}$ ao solo, porém a magnitude das respostas variou entre as espécies. Teyker et al. (1991) constataram que plantas de Amaranthus retroflexus que cresceram em associação com plantas de milho acumularam 2,5 vezes mais $\mathrm{N}$, em relação a essa cultura, quando altos níveis desse elemento eram fornecidos. Admitindo-se que a produção de massa seca constitui-se em bom indicador para se avaliar a capacidade adaptativa de uma planta a determinado ambiente, pode-se inferir que a espécie de plantas daninhas apresentam grande plasticidade adaptativa. Concordando com as afirmações de Procópio et al. (2004) em que o fornecimento de $\mathrm{N}$ favorece as espécies em detrimento das culturas, o manejo inadequado desse nutriente pode agravar o problema da matocompetição diante das culturas. E a capacidade que as plantas daninhas possuem para se desenvolver e extrair nutrientes do solo serão fatores preponderantes para o sucesso dessas plantas em comunidades cultivadas.

$\mathrm{Na}$ Tabela 5 são apresentadas as espécies de plantas daninhas presentes nos diferentes manejos de solo, aos 35 dias após a emergência do feijão, os quais apresentaram composição florística semelhante, diferindo no aparecimento de algumas espécies e na densidade.

É oportuno salientar que a espécie daninha Cyperus rotundus L. esteve presente em todos os tratamentos de manejo de solo, mas com maior porcentagem de ocorrência no manejo do solo com crotalária. Isso pode ser explicado pelo fato de que a espécie C.juncea é bastante eficiente no acúmulo e liberação do nitrogênio, sendo que a maior parte do $\mathrm{N}$ contido na fitomassa está localizada nos talos mais jovens e na parte mais externa dos talos mais velhos (células vivas); estes materiais são os primeiros a serem atacados e decompostos pelos microorganismos. Desta forma, a liberação acelerada associada à rápida absorção pela espécie daninha Cyperus rotundus $L$., acarreta alta competitividade por parte da planta daninha, e conseqüentemente grande produção de massa seca. Contudo, é importante ressaltar que a dinâmica de liberação do nitrogênio pela crotalária pode ser muito útil para as culturas de inverno, especialmente o feijoeiro, desde que sejam semeados imediatamente após o seu manejo.

Tabela 4 - Produção de massa seca das plantas daninhas (MSPD), Número de espécies de plantas daninhas (NE), Número total de plantas daninhas (NT) e Porcentagem de incidência de plantas daninhas (PI) nos diferentes manejos de solo

\begin{tabular}{|c|c|c|c|c|}
\hline Tratamento & MSPD (g) & $\mathrm{NE}\left(\mathrm{m}^{2}\right)$ & $\mathrm{NT}\left(\mathrm{m}^{2}\right)$ & PI $(\%)$ \\
\hline \multicolumn{5}{|c|}{ Manejo do solo ${ }^{(1)}$} \\
\hline $\mathrm{CI}$ & $31,9 \mathrm{~b}$ & $2,4 \mathrm{~b}$ & $12,1 \mathrm{~b}$ & $20,1 \mathrm{~b}$ \\
\hline MI & $52,1 \mathrm{~b}$ & $4,1 \mathrm{ab}$ & $19,8 \mathrm{~b}$ & $37,4 \mathrm{~b}$ \\
\hline EI & $80,8 \mathrm{a}$ & $5,5 \mathrm{a}$ & $31,8 \mathrm{~b}$ & $62,6 \mathrm{~b}$ \\
\hline $\mathrm{SC}$ & 82,6 a & $6,6 \mathrm{a}$ & $33,6 \mathrm{a}$ & $66,4 \mathrm{a}$ \\
\hline Teste F & $30,9 *$ & $37,4^{*}$ & $38,4^{*}$ & $48,8^{*}$ \\
\hline \multicolumn{5}{|c|}{ Manejo do $\mathrm{N}^{(2)}$} \\
\hline $\mathrm{CN}$ & $78,1 \mathrm{a}$ & $5,1 \mathrm{a}$ & $25,8 \mathrm{a}$ & $50,0 \mathrm{a}$ \\
\hline SN & $45,6 \mathrm{~b}$ & $4,2 \mathrm{a}$ & $22,8 \mathrm{a}$ & $43,2 \mathrm{a}$ \\
\hline Teste F & $5,47 *$ & $7,35^{*}$ & $3,3^{\mathrm{NS}}$ & $4,6^{*}$ \\
\hline CV (\%) & 20,0 & 18,2 & 19,12 & 19,0 \\
\hline
\end{tabular}

${ }^{(1)} \mathrm{CI}$ : Crotalaria incorporada; MI: Milheto incorporado; EI: Espontâneas incorporadas; SC: Sem cobertura. ${ }^{(2)} \mathrm{CN}$ : Com nitrogênio; SN: Sem nitrogênio; *Significativo a 5\% de significância ${ }^{\mathrm{NS}}$ não significativo 
Tabela 5 - Espécies de plantas daninhas e percentagem de participação - PP (\%) de espécie nos diferentes manejos de solo

\begin{tabular}{|c|c|c|c|c|}
\hline Tratamento & Nome científico & Família & Nome comum & PP \\
\hline \multirow{10}{*}{ MI } & Cyperus rotundus $L$ & Cyperaceae & Tiririca & 54 \\
\hline & Commelina benghalensis L. & Commelinaceae & Trapoeraba & 6 \\
\hline & Panicum maximum & Poaceae & Colonião & 19 \\
\hline & Portuca oleracea L. & Portulacaceae & Beldroega & 5 \\
\hline & Bidens pilosa $L$. & Asteraceae & Picão-preto & 3 \\
\hline & Emilia fosbergii & Asteraceae & Falsa-serralha & 3 \\
\hline & Silene gallica $L$. & Caryophyllaceae & Alfinete & 3 \\
\hline & Euphorbia heterophylla L. & Euphorbiaceae & Leiteiro & 3 \\
\hline & Cenchrus echinatus $L$. & Poaceae & Tibete & 2 \\
\hline & Amaranthus deflexus & Amaranthaceae & Caruru & 2 \\
\hline \multirow{10}{*}{ EI } & Cyperus rotundus $L$ & Cyperaceae & Tiririca & 51 \\
\hline & Commelina benghalensis L. & Commelinaceae & Trapoeraba & 7 \\
\hline & Panicum maximum & Poaceae & Colonião & 16 \\
\hline & Portuca oleracea L. & Portulacaceae & Beldroega & 3 \\
\hline & Bidens pilosa L. & Asteraceae & Picão-preto & 3 \\
\hline & Emilia fosbergii & Asteraceae & Falsa-serralha & 2 \\
\hline & Silene gallica L. & Caryophyllaceae & Alfinete & 4 \\
\hline & Euphorbia heterophylla L. & Euphorbiaceae & Leiteiro & 4 \\
\hline & Cenchrus echinatus $L$. & Poaceae & Tibete & 9 \\
\hline & Amaranthus deflexus & Amaranthaceae & Caruru & 1 \\
\hline \multirow{10}{*}{$\mathrm{SC}$} & Cyperus rotundus $L$ & Cyperaceae & Tiririca & 42 \\
\hline & Commelina benghalensis L. & Commelinaceae & Trapoeraba & 9 \\
\hline & Panicum maximum & Poaceae & Colonião & 14 \\
\hline & Portuca oleracea L. & Portulacaceae & Beldroega & 3 \\
\hline & Bidens pilosa L. & Asteraceae & Picão-preto & 5 \\
\hline & Emilia fosbergii & Asteraceae & Falsa-serralha & 1 \\
\hline & Silene gallica $L$. & Caryophyllaceae & Alfinete & 9 \\
\hline & Euphorbia heterophylla L. & Euphorbiaceae & Leiteiro & 3 \\
\hline & Cenchrus echinatus $L$. & Poaceae & Tibete & 11 \\
\hline & Amaranthus deflexus & Amaranthaceae & Caruru & 3 \\
\hline \multirow{6}{*}{$\mathrm{CI}$} & Cyperus rotundus $L$ & Cyperaceae & Tiririca & 74 \\
\hline & Commelina benghalensis L. & Commelinaceae & Trapoeraba & 6 \\
\hline & Panicum maximum & Poaceae & Colonião & 5 \\
\hline & Portuca oleracea L. & Portulacaceae & Beldroega & 5 \\
\hline & Bidens pilosa L. & Asteraceae & Picão-preto & 6 \\
\hline & Silene gallica $L$. & Caryophyllaceae & Alfinete & 3 \\
\hline
\end{tabular}

MI: Milheto incorporado; EI: Espontâneas incorporadas; SC: Sem cobertura; CI: Crotalaria incorporada 


\section{Conclusões}

1. O manejo do solo com crotalaria conferiu maior supressão às plantas daninhas, devido à quantidade de massa no solo;

2. A adubação nitrogenada em cobertura na cultura do feijão influenciou significativamente a produção de massa seca pelas plantas daninhas;

3.Aliberaçãoaceleradadonitrogêniopelacrotalariafavorece a ocorrência e o estabelecimento de algumas espécies de plantas daninhas, conferindo alta competitividade por parte da planta daninha, e conseqüentemente favorecendo a produção de massa seca.

\section{Agradecimentos}

Os autores agradecem à Universidade Estadual de Mato Grosso do Sul - UEMS e à CAPES pela disponibilização de recursos e bolsa de mestrado ao primeiro e segundo autores.

\section{Referências}

BLACKSHAW, R. Differential response of weed species to added nitrogen. Weed Science, v. 51, n. 06, p. 532-539, 2003.

CALEGARI, A. Espécies para cobertura de solo. In: CALEGARI, A. Plantio Direto: pequena propriedade sustentável. Londrina: IAPAR, 1998. 255 p. (IAPAR. Circular, 101).

EMPRESA BRASILEIRA DE PESQUISA AGROPECUÁRIA EMBRAPA. Sistema brasileiro de classificação de solos. 2. ed. Rio de Janeiro: Centro Nacional de Pesquisa de Solos, 2006. 306 p.

FAVERO, C. et al. Modificações na população de plantas espontâneas na presença de adubos verdes. Pesquisa Agropecuária Brasileira, v. 36, n.11, p. 1355-1362, 2001.

JAKELAITIS, A. et al. Efeitos de sistemas de manejo sobre a população de tiririca. Planta Daninha, v. 21, n. 01, p.89-95, 2003.
LINDQUIST, J. L. et al. Effect of Nitrogen Addition and Weed Interference on Soil Nitrogen and Corn Nitrogen Nutrition Weed Technology, v.24, n.01, p.50-58, 2010.

MESCHEDE, D. K.; FERREIRA, A. B.; RIBEIROJR., C. C. Avaliação de diferentes coberturas na supressão de plantas daninhas no cerrado. Planta Daninha, v. 25, n.03, p. 465-471, 2007.

MONQUERO, P. A. et al. Efeito de adubos verdes na supressão de espécies de plantas daninhas. Planta Daninha, v. 27, n.01, p.85-95, 2009.

PROCÓPIO, S. O. et al. Absorção e utilização do nitrogênio pelas culturas da soja e do feijão e por plantas daninhas. Planta Daninha, v.22, n.03, p. 365-374, 2004.

ROSOLEM, C. A. Nutrição e adubação do feijoeiro. Piracicaba: Potafos, 1987. 93p. (Boletim Técnico, 8).

SHAFIQ, M. Crop yields and nutrient uptake by rainfed wheat and mungbean as affected by tillage, fertilization, and weeding. Journal Plant Nutrition, v. 17, n.01, p. 561-577, 1994.

RADOSEVICH, S. R.; HOLT, J.; GHERSA, C. Physiological aspects of competition. In: RADOSEVICH, S. R.; HOLT, J.; GHERSA, C. Weed ecology: Implication for managements. New York: John Willey \& Sons, 1996. p.217-301.

STONE, L. F.; MOREIRA, J. A. A. Efeitos de sistemas de preparo do solo no uso de água e na produtividade do feijoeiro. Pesquisa Agropecuária Brasileira, v.35, n.04, p.835-841, 2000.

TEYKER, R. H.; HOELZER, H. D.; LIEBL, R. A. Maize and pigweed response to nitrogen supply and form. Plant Soil, v. 135, p. 287-292, 1991.

THEISEN, G.; VIDAL, R. A.; FLECK, N. G. Redução da infestação de Brachiaria plantaginea em soja pela cobertura do solo com palha de aveia preta. Pesquisa Agropecuária Brasileira, v.35, p.753-756, 2000.

VIANELLO, R. L.; ALVES, A. R. Meteorologia básica e aplicações. Viçosa: Impressão Universitária, 1991. p.395-399.

VIDAL, R. A.; TREZZI, M. M. Potencial da utilização de coberturas vegetais de sorgo e milheto na supressão de plantas daninhas em condição de campo: I - plantas em desenvolvimento vegetativo. Planta Daninha, v. 22, n.02, p. 217-233, 2004. 